http://jmscr.igmpublication.org/home/ ISSN (e)-2347-176x ISSN (p) 2455-0450 crossref DOI: https://dx.doi.org/10.18535/jmscr/v8i3.72

\title{
Comparison of Extra cranial Carotid Duplex Doppler in Anterior Circulation Stroke and Non-Stroke Patients
}

\author{
Authors \\ Murali $^{\text {1* }}$, Vinod $^{2}$, Jagadeep $^{3}$
}

${ }^{1}$ Radiology resident, Sree Mookambika Institute of Medical Sciences, Kanyakumari

${ }^{2}$ AssociateProfessor, Department of Radiodiagnosis, Sree Mookambika Institute of Medical Sciences Kanyakumari

${ }^{3}$ Assistant Professor, Department of Radiodiagnosis, Sree Mookambika Institute of Medical Sciences, Kanyakumari

*Corresponding Author

Dr R.Murali

Junior Resident, Department of Radiodiagnosis, Sree Mookambika Institute of Medical Sciences, Kulasekharam,

Kanyakumari, India

Abstract
Background: Cerebrovascular disease is a life threatening and debilitating neurological disease with
significant morbidity
Aims \& Objectives: To compare the common carotid artery intima media thickness in patients with
anterior circulation stroke with non-stroke patients.
Materials and Methods: All patients with CT/ MRI proven anterior circulation stroke and who full fill
inclusion criteria.
Non stroke patients who come for USG neck will be taken as the comparison group.
Results: CAIMT is a reliable independent marker for the early detection of atherosclerosis. Plaque
characteristics determined the incidence of infarcts in case group rather than degree of stenosis in the
internal carotid arteries. Prevalence of severe stenosis (>70\%) was low while the prevalence of mild
stenosis (< 50\%) in the case group was statistically high. Stenosis was more profound in terms of
frequency and severity in men at all ages than women.
Conclusion: Carotid Doppler is a cost effective, non- invasive technique to assess the carotids without
radiation hazard but operator dependent. Easy availability with hemodynamic, anatomic information and
directional blood flow helps in improved accuracy in quantifying stenosis.

\section{Introduction}

Stroke is defined as a sudden onset of focal neurological deficit lasting for more than 24 hours with no apparent cause other than vascular origin. The 24 hours threshold in the definition excludes Transient Ischemic Attacks (TIA) ${ }^{[1]}$. Stroke is classified depending upon its aetiology into either ischemic stroke $(85 \%)$ or haemorrhagic stroke (15\%) Ischemic stroke can be classified into anterior circulation or posterior circulation territories. The anterior circulation consists of the right and left internal carotid arteries which bifurcates into the anterior cerebral artery (ACA) and middle cerebral artery (MCA). Middle cerebral artery occlusion is the most common cause of severe stroke as it supplies the largest proportion of the brain ${ }^{[2]}$ about $80 \%$ of strokes are thromboembolic in origin and the embolus arises from the carotid plaque ${ }^{[3]}$. Progressive atherosclerotic disease results into pathological 
intimal thickening, fibrous cap atheroma and plaque formation. Early detection helps to control the disease in patients who are at risk ${ }^{[4]}$. Early detection of the atheromatous changes in the carotid artery will reduce the stroke related morbidity and mortality. Sonographic evaluation of the carotid arteries, are used for risk assessment; on gray scale, CIMT in common carotid artery is evaluated on gray scale ultrasound $^{[5]}$. The plaques are characterized as echogenic, calcified or hypoechoic or associated with intraplaque haemorrhage and surface ulceration and percentage stenosis ${ }^{[6]}$. The North American Symptomatic Carotid Endarterectomy Trial (NASCET) and European Carotid Surgery Trialists (ECST) collaborative group showed a benefit of carotid endarterectomy for recently symptomatic patients with internal carotid lumen diameter narrowing of $70 \%$ or more ${ }^{[7]}$.

\section{Aim}

To compare the common carotid artery intima media thickness in patients with anterior circulation stroke with non-stroke patients.

\section{Objectives}

Primary Objective: To describe the carotid artery plaque characteristics with CT/ MRI proven anterior circulation stroke with non-stroke patients.

Secondary Objective: To assess the proportion of Common Carotid Artery (CCA) and Internal Carotid Artery (ICA) stenosis with the help of carotid duplex sonography in patients of both the groups.

\section{Materials and Methods}

Study Design: Comparative Cross sectional study- diagnostic test evaluation

Study Period: From January 2018 - October 2019

Study Setting: Department of Radiodiagnosis, Sree Mookambika Institute of Medical Sciences, Kulasekharam.
Study Population: All patients with CT/ MRI proven anterior circulation stroke and who full fill inclusion criteria.

Non stroke patients who come for USG neck will be taken as the comparison group.

Inclusion Criteria: All patients above 18 years of age with CT / MRI proven acute, sub acute and chronic anterior circulation stroke who also undergo for carotid Doppler evaluation.

All adult non stroke patients who come for USG neck.

\section{Exclusion Criteria}

- Comatose or critically ill patients.

- CT/MRI showing hemorrhagic infarct.

- Lacunar infarcts on CT.

- Posterior circulation stroke.

Study Sample Size: 100

\section{Statistical Analysis}

Details of all patients including the CT / MRI diagnosis was entered in a proforma, the data documented in Microsoft Excel and processed using SSPS for Windows, Version 17. Variables were plotted and analyzed using Chi square and Fisher exact test.

A P-value less than 0.05 was considered statistically significant. All qualitative variables expressed as percentage (\%) in both stroke and non-stroke groups.

All quantitative variables expressed as mean (SD) in both stroke and non-stroke groups. Thickness mean and SD

Plaque characteristics- percentage of patients having echogenic, ulcerations, hypoechoic, calcifications.

Percentage of patients having stenosis as per NASCET score. Each of the sonological features were analyzed to determine its association with CT / MRI brain findings.

\section{Results and Discussion}

The current study was done to assess extra cranial carotid vessels by carotid duplex Sonography among the population who presented with 
cerebrovascular insufficiency and comparing those group with asymptomatic individuals.

CAIMT is a reliable independent marker for the early detection of atherosclerosis. Atherosclerotic plaques were mostly found at the site of proximal internal carotid artery, carotid bifurcation followed by carotid bulb.

Maximum mean wall thickness of common carotid artery was predominantly found to be associated with risk factors like diabetes mellitus, Dyslipidemia and hypertension; however, hypertension is an independent risk factor.

Maximum mean wall thickness of Internal Carotid Artery showed strong positive association with Hypertension and history of Heart Disease.

Plaque characteristics determined the incidence of infarcts in case group rather than degree of stenosis in the internal carotid arteries. Similarly, the degree of stenosis in the ICA does not make any statistical difference in the incidence of stroke involving both ACA and MCA.

Prevalence of severe stenosis $(>70 \%)$ was low while the prevalence of mild stenosis $(<50 \%)$ in the case group was statistically high which also substantiated that plaque characteristics as the independent variable in predicting the risk of future stroke.

Stenosis was more profound in terms of frequency and severity in men at all ages than women. ICA/ CCA EDV Ratio had less specificity as compared to the ICA/ CCA PSV ratio.

Case 1

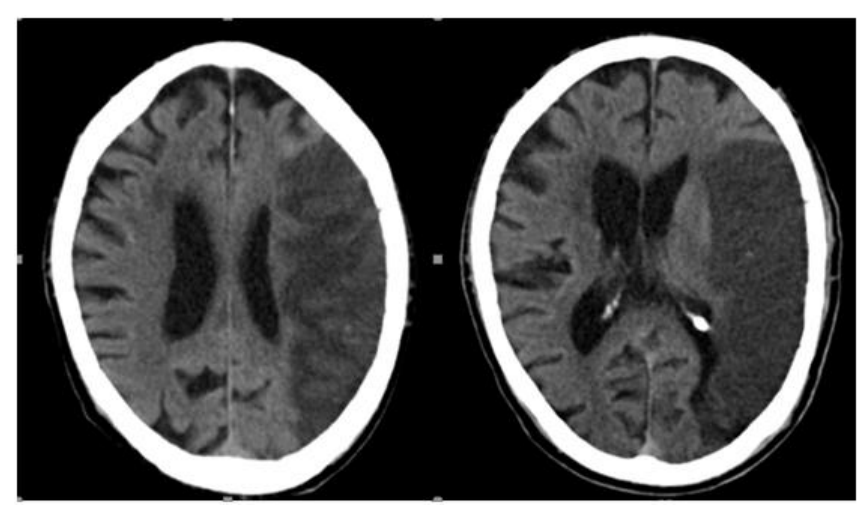

74 year old male with right sided weakness. NECT showed a large wedge shaped hypodense area noted involving the left fronto parietal region -Left MCA territory - Acute Infarct

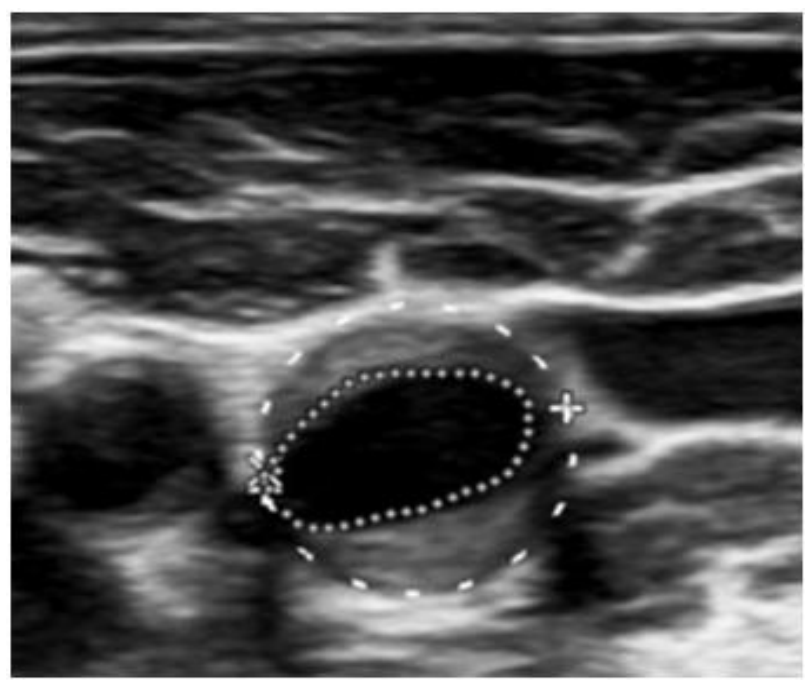

Ultrasound -transverse B mode grey scale image shows a homogenous plaque causing mild to moderate stenosis $(58 \%)$ in distal CCA

Case 2

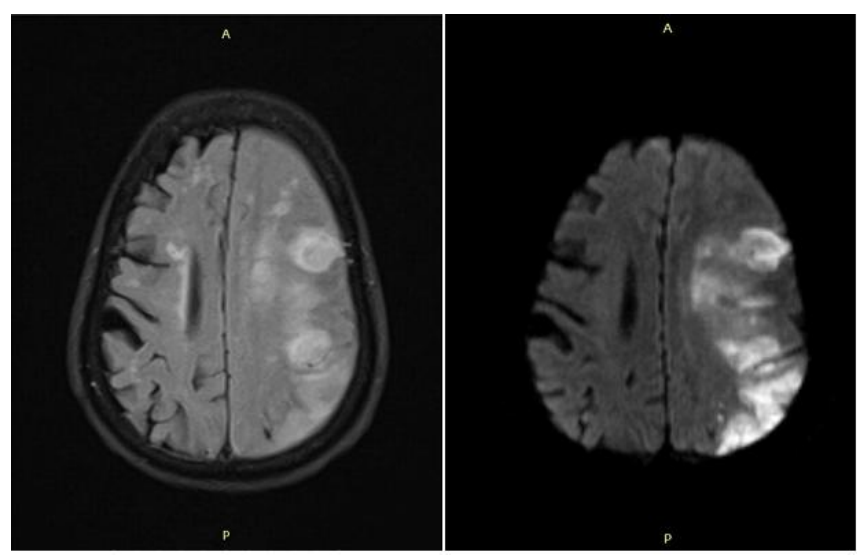

77-year-old patient with right hemiparesis. Axial FLAIR and Diffusion Weighted MR images shows, Left - ill-defined hyperintense areas in left fronto parietal region. Right - diffusion restriction in left fronto parietal region - Acute infarct Left ACA territory.

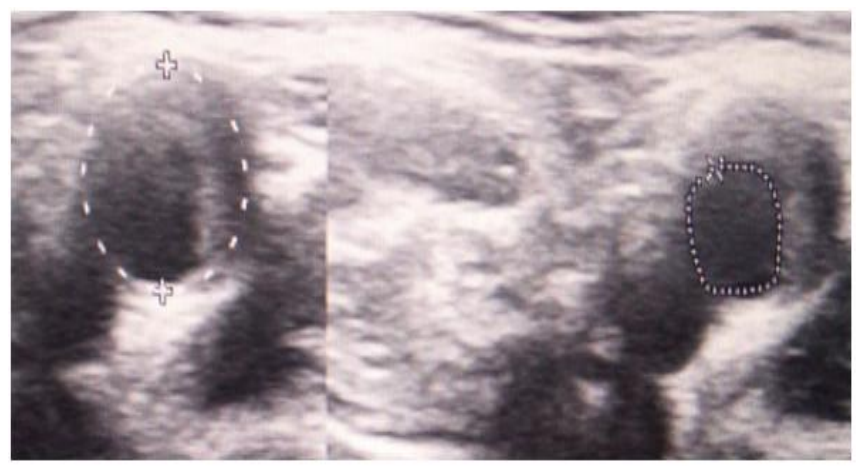

Ultrasound Transverse image showing severe occlusion in left ICA 


\section{Case 3}

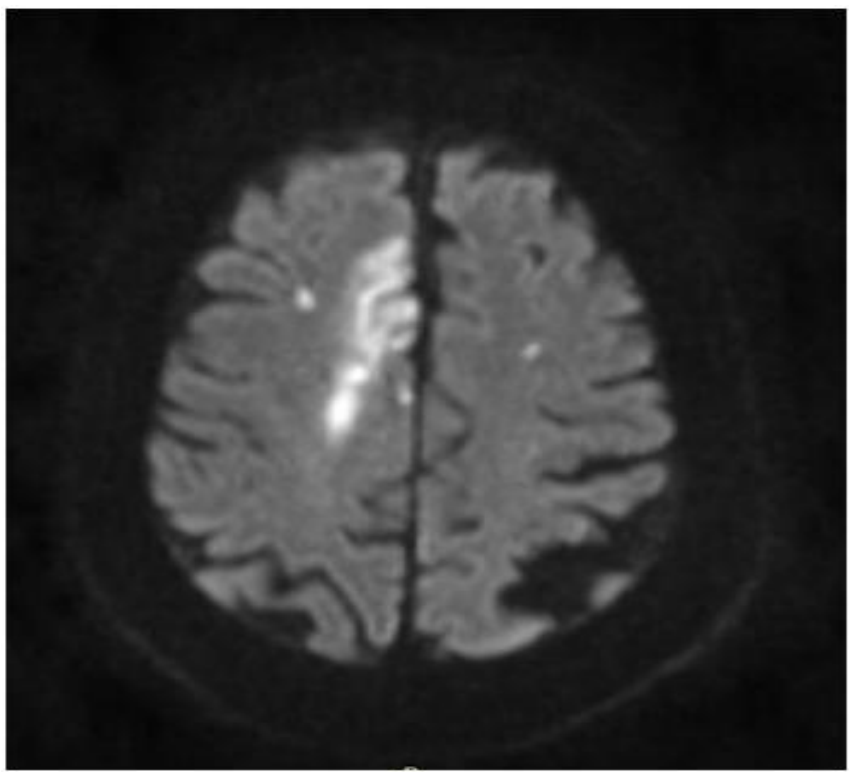

72-year-old man with left hemiparesis. Axial Diffusion Weighted MR images showing diffusion restriction in medial and superior frontal gyrus and white matter - Acute infarct - Right ACA territory. Few punctate foci of diffusion restriction also seen in bilateral centrum semiovale

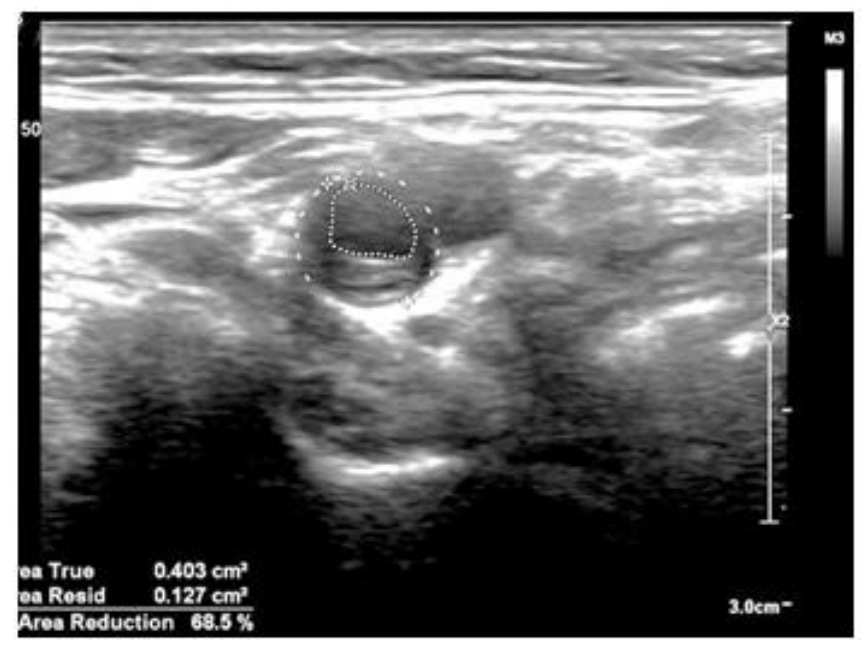

Ultrasound -transverse B mode grey scale image showing moderate carotid stenosis (69\%) at the level of right carotid bulb.

\section{Conclusion}

Hence carotid Doppler is a cost effective, noninvasive technique to assess the carotids without radiation hazard but operator dependent. Easy availability with hemodynamic, anatomic information and directional blood flow helps in improved accuracy in quantifying stenosis.

\section{Limitations}

Operator dependent

Patients with anatomical variants of carotid vessels

Colour Doppler is angle dependent and less resolution than gray scale.

Calcified plaque in a carotid artery obscured the area of examination due to its posterior acoustic shadowing. However, the change in position to postero-lateral view was helpful in some cases, especially those involving the smaller segment of vessels

\section{References}

1. Smith WS, English JD, Johnston SC. Cerebrovascular Diseases. In: Longo DL,Fauci AS, Kasper DL, Hauser SL, Jameson JL, Loscalzo J(eds). Harrisons's Principles of Internal Medicine (18th edn.) McGraw-Hill 2012;3271-78.

2. Rumack CM, Wilson SR, Charboneau JW, Levine D. The extracranial cerebral vessels In: Diagnostic Ultrasound (4th ed.) Elsevier-Mosby 2010; 948-49.

3. Donnan GA, Fisher M, Macleod M, Davis SM. Stroke. Lancet.2008;371(9624):161223.

4. Touboul PJ, Labreuche J, Vicaut E, Amarenco P. Genic Investigators. Carotid intima-media thickness, plaques, and Framingham risk score as independent determinants of stroke risk. Stroke. 2005;36:1741-45.

5. Polak JF, O'Leary DH. Intima-media thickness: a tool for atherosclerosis imaging and event prediction. The American Journal of Cardiology. 2002;14:244-69.

6. Sitzer M, Müller W, Siebler M, Hort W. Plaque ulceration and lumen thrombus are the main sources of cerebral microemboli in high-grade internal carotid artery stenosis. Am Heart Assoc. 1995;8:456-61.

7. Fernandes M, Keerthiraj B, Mahale AR, Kumar A, Dudekula A. Evaluation of 
carotid arteries in stroke patients using colour Doppler sonography: A prospective study conducted in a tertiary care hospital in South India. Int J Appl Basic Med Res. 2016;6(1):38-44. 